\title{
An Approach to Prevent Air Pollution and Generate Electricity Using Nanostructured Carbon Materials
}

\author{
Samrat Mondal, MBC Institute of Engineering and Technology, India \\ Avishek Bhadra, MBC Institute of Engineering and Technology, India \\ Souvik Chakraborty, MBC Institute of Engineering and Technology, India \\ Suraj Prasad, MBC Institute of Engineering and Technology, India \\ Shouvik Chakraborty, University of Kalyani, India \\ (iD https://orcid.org/0000-0002-3427-7492
}

\begin{abstract}
Pollution is one of the major threats for the environment as well as society. It causes severe problems for the living organisms and can give birth to various unknown issues. Different sources like cars, industrial belts, fossil fuels, etc. are the major causes of air pollution. Different researchers are working to develop new methods to combat air pollution. The domain of nanotechnology is emerging day-by-day, and different fields are supported by the blessing of nanotechnology. Application of nanotechnology can also be helpful in reducing air pollution as well as producing electricity. The main objective of this article is to propose a novel concept to generate electricity and reduce air pollution with the help of the nanotechnology. In this work, a new solution is proposed to fight against air pollution. The proposed solution is based on nanotechnology which fight against air pollution and can generate electricity using the nanostructured carbon materials. The proposed solution can be deployed in a real-life scenario to reduce the air pollution and produce electricity in a large scale to provide an alternate energy resource to society.
\end{abstract}

\section{KEYWORDS}

Air Pollution, Electricity, Energy Conservation, Nanostructures, Nanotechnology

\section{INTRODUCTION}

The issue of environmental pollution has become a vital issue and one of major concerns of the today's world. It is mainly caused by toxic chemicals and includes air, water pollution and many more. This pollution results in degradation of human health. With the advancement in technology, various methods are applied in real life to handle this situation. Pollution becomes a social curse and whole world is under this threat (Dockery \& Pope III, 1994). Various researchers across the globe are working in this domain to find an effective solution. Nanotechnology is one of the emerging technologies that offers many ways to fight with this problem. Nanotechnology is the study, process, and manipulation of materials at a molecular level. Nanotechnology has four major functions as follows: clean-up and purification, detection of contaminants, pollution prevention and maybe used to generate electricity (Fleischer \& Grunwald, 2008). In today's world where industries have been

DOI: 10.4018/IJANR.20210101.oa1

This article published as an Open Access article distributed under the terms of the Creative Commons Attribution License (http://creativecommons.org/licenses/by/4.0/) which permits unrestricted use, distribution, and production in any medium, provided the author of the original work and original publication source are properly credited. 
so advanced that our environment is filled with pollutants which are coming directly or indirectly from human activities. Human activities such as oil, coal, gas combustion and contaminants emitted from vehicles pollutes the air. Water pollution caused by waste disposal, oil spills and by-products of industrial processes. Thus, we need a technology that can clean the contaminants and use them in an appropriate way (e.g., to produce electricity) and improve the quality of the environment. With the advancement of technology, various efficient methods are gradually developing to solve and handle several problems in a cost effective manner (S. Chakraborty et al., 2016; S. Chakraborty, Mali, Banerjee, et al., 2018; S. Chakraborty \& Bhowmik, 2015; Shouvik Chakraborty et al., 2016; Shouvik Chakraborty, Chatterjee, Ashour, et al., 2017; Shouvik Chakraborty, Chatterjee, Dey, et al., 2017; Shouvik Chakraborty et al., 2020, 2015; Shouvik Chakraborty, Mali, et al., 2017; Shouvik Chakraborty \& Bhowmik, 2015, 2013; Shouvik Chakraborty \& Mali, 2018; Datta et al., 2017; Fang et al., 2009; S. Hore et al., 2016, 2018; Sirshendu Hore et al., 2015; Lu et al., 2012; Mali, Chakraborty, \& Roy, 2015; Mali, Chakraborty, Seal, et al., 2015; M. Roy et al., 2018; Mousomi Roy et al., 2019, 2017; Sarddar et al., 2015; Seal et al., 2017). The machine learning-based approaches are frequently used in different application domain to solve various problems efficiently. Machine learning is a branch of artificial intelligence that allows machines to behave intelligently (S. Chakraborty, Mali, Chatterjee, et al., 2018; Shouvik Chakraborty, 2020; Shouvik Chakraborty \& Mali, 2020a, 2020b, 2020c, 2021; Miller \& Brown, 2018; Mondal et al., 2021). With no exception, nanostructure based designs also exploits the advantages of the machine learning on several occasions that proves to be highly effective (Bioinspired Intelligent Nanostructured Interfacial Materials - Lei Jiang, Lin Feng - Google Books, n.d.). Although this article does not incorporate the concept of machine learning systems but it will be an interesting future work and the real-life implementation of this work can be benefitted with the blessings of machine learning based nanostructure systems.

Nanotechnology is used to prevent the formation of pollutants by using nanomaterials (Baruah \& Dutta, 2009; Silva et al., 2017; Yang et al., 2015). Nanomaterial is very small in size and the ratio of the surface area to the volume is high so that it can be used to detect very sensitive contaminants. These nanomaterials are magnet dependent and therefore, magnets can be used to determine the direction. So, any flying device like a drone which is equipped with camera and magnet attached in it, can be used in seas and other water-bodies to determine the direction and prevent water pollution. In this article, a method is proposed to prevent air pollution and generate electricity using nanotechnology. Carbon which are collected from the pollutants emitted from vehicles is deposited on a quartz substrate of carbon nanotube (CNT). The device is inserted in deionized water to generate electricity from water evaporation and thus decreasing air pollution (Pummakarnchana et al., 2005). Structure of some nanostructured carbon materials is given in Figure 1.

\section{PROPOSED SOLUTION}

Water evaporation is a natural process that harvests thermal energy from the ambient environment. Here, it is shown that water evaporation from the surface of a variety of nanostructured carbon materials can be used to generate electricity. It is found that evaporation from centimeter-sized carbon black sheets can generate sustained voltages. The interaction between water molecules and the carbon layers with evaporation induced water flow within the porous carbon nanotube is the key to generate electricity.

Air pollution has serious effects on health and can have deadly situation if a person resides in a polluted environment for a long period of time which includes heart problems, lung cancer, respiratory problems etc. It also causes damage to brain, liver and nerves of living organisms. Scientists suspects that it causes birth defects too. Air pollution is caused by emission from vehicles, combustion of fossil fuels and household pollutants. There are many ways to control air pollution but still it is may not be always possible to control. 


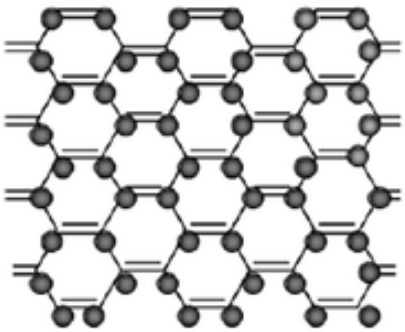

Graphene

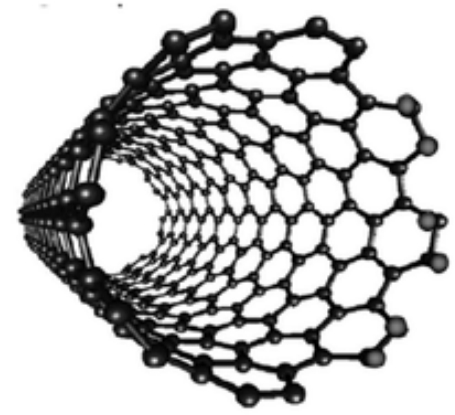

Carbon nanotube

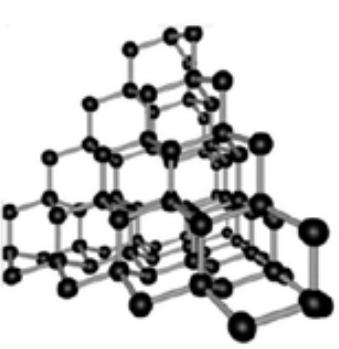

Diamond

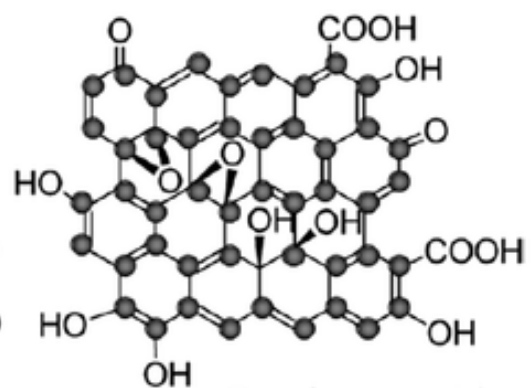

Graphene oxide

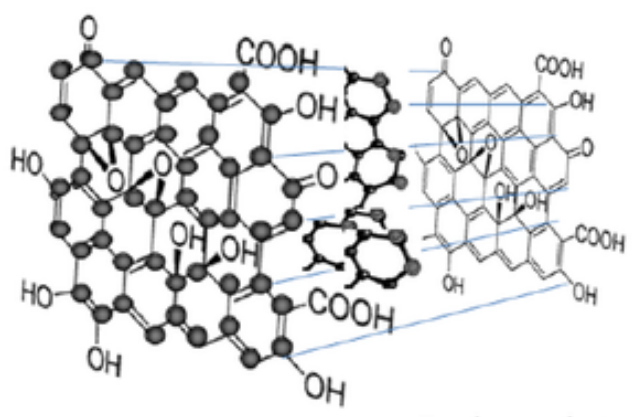

Carbon dot

There are two major ways in which nanotechnology is being used to reduce air pollution. First one is the use of catalysts and second one is the use of nanostructured membranes. Catalysts can be used to accelerate a chemical reaction at lower temperatures or make the reaction more effective and efficient. Nanotechnology can improve the performance of catalysts which are used to transform vapors escaping from vehicles and industrial plants. That's because catalysts are constructed with nanoparticles and have a greater surface area to react with chemicals rather than catalysts which are made-up with larger particles. Nanostructured carbon materials are used to combat air pollution. The proposed solution to prevent air pollution and generate electricity is with nanostructure carbon materials is given in below. A graphical representation of the proposed solution can be visualized from Figure 2.

To begin the process, graphite powder needs to be immersed in a mixed solution of nitric and sulphuric acid with potassium chlorate. Carbon nanotube bundles which are also known as CNT can be obtained from this solution after heating the solution upto $70^{\circ}$ centigrade and leaving them in the air for 3 days. Water evaporation is a crucial step in the natural water circulation, releasing a huge amount of energy. Evaporation from the surface of a variety of nanostructured carbon materials can be used to generate electricity and sustained voltages upto $1 \mathrm{~V}$ for a few days. The evaporation driven water flows through nano porous carbon and convert thermal energy into electricity via the water molecules interaction with the carbon material. The annealing and plasma treatment are essential for the electricity generation. The device consists of carbon black sheet and CNT electrodes on a quartz substrate or it is fabricated using carbon black and glass fiber. After the carbon black sheet is deposited on the glass fiber, it is ready to go through a process which is known as annealing. Annealing is the process to heat the device and then allowing it to cool down slowly, in order to remove internal stresses and toughen the device. After the completion of this process, it goes through plasma treatment where it is used to clean non-metal materials. Oxygen cleans organics and is capable of surface modification. 


\section{- Electrode Printing}

- Carbon Black deposition

- Annealing

- Plasma treatment or cleaning

- Generate Electricity

Two wires are taken from the electrodes and then the device is inserted into the deionized water, for which voltage between two electrodes is generated.

The device maybe connected with a supercapacitor also, which is a type of a capacitor that can store a large amount of energy compared to electrolytic capacitors. The supercapacitor can store the electric energy which is generated from the glass-fiber-carbon-nanoparticle film and provide a large current output. The supercapacitor can be charged by the output voltage of glass-fiber-carbonnanoparticle film and then a LED can be lighted up. Four devices in series connection can also power a liquid crystal display.

As water evaporation from carbon materials or the device can be enhanced, it is possible to design devices with enhanced electricity generation that can be used in many ways. The device can be used behind a vehicle from where pollutants are emitted, so that, carbon is deposited in the device from which electricity can be generated and can charge the battery of the car or can be used in other ways. It can also be used in industries where there is a large amount of pollution due to combustion and this device can reduce the pollution and generate electricity. Coal mines are the places where large amount of carbon is emitted in the atmosphere. So, using this glass-fibre-carbon-nanoparticle film the emitted carbon can be used to generate electricity.

\section{CONCLUSION, CHALLENGES, AND FUTURE SCOPE}

Pollution is really one of the prime challenges of the world which needs to be defeated. Pollution can reduce the lifespan of the human beings and also can disrupt the normal lifestyle of the common people. Energy conservation is another common issue and challenge. In this work, a nanotechnology-based solution is presented to solve both the problems to some extent. The proposed method can effectively control the air pollution and can generate electricity. The proposed solution can be extended further to develop a device with better mechanical properties and higher electricity energy output with compared to this one. Moreover, further research can be carried out to investigate the interaction between water molecules and carbon to find different phenomena and various other properties of the same. 


\section{REFERENCES}

Baruah, S., \& Dutta, J. (2009). Nanotechnology applications in pollution sensing and degradation in agriculture. In Environmental Chemistry Letters (Vol. 7, Issue 3, pp. 191-204). Springer. doi:10.1007/s10311-009-0228-8

Bioinspired Intelligent Nanostructured Interfacial Materials. (n.d.). Retrieved May 13, 2021, from https://books. google.co.in/books?hl=en\&lr=\&id=J-BIJNJsfycC\&oi=fnd\&pg=PR5\&dq=machine+intelligence + in + nanos tructure+electricity+construction\&ots=gzT-gG6nIU\&sig=vIJhjXrzclwECh-K0f3r7SILWdY\#v=onepage\&q $\& \mathrm{f}=$ false

Chakraborty, S., Seal, A., \& Roy, M. (2015). An Elitist Model for Obtaining Alignment of Multiple Sequences using Genetic Algorithm. 2nd National Conference NCETAS 2015, 4(9), 61-67.

Chakraborty, S., Roy, M., \& Hore, S. (2016). A Study on Different Edge Detection Techniques in Digital Image Processing. In Feature Detectors and Motion Detection in Video Processing (pp. 100-122). IGI Global. doi:10.4018/978-1-5225-1025-3.ch005

Chakraborty, S., Chatterjee, S., Ashour, A. S., Mali, K., \& Dey, N. (2017). Intelligent Computing in Medical Imaging: A Study. In N. Dey (Ed.), Advancements in Applied Metaheuristic Computing (pp. 143-163). IGI Global. doi:10.4018/978-1-5225-4151-6.ch006

Chakraborty, S., Mali, K., Chatterjee, S., Banerjee, S., Mazumdar, K. G., Debnath, M., Basu, P., Bose, S., \& Roy, K. (2017). Detection of skin disease using metaheuristic supported artificial neural networks. 2017 8th Annual Industrial Automation and Electromechanical Engineering Conference (IEMECON), 224-229. doi:10.1109/ IEMECON.2017.8079594

Chakraborty, S., \& Mali, K. (2018). Application of Multiobjective Optimization Techniques in Biomedical Image Segmentation-A Study. In Multi-Objective Optimization (pp. 181-194). Springer Singapore. 10.1007/978981-13-1471-1_8

Chakraborty, S. (2020). An Advanced Approach to Detect Edges of Digital Images for Image Segmentation. In Applications of Advanced Machine Intelligence in Computer Vision and Object Recognition: Emerging Research and Opportunities. IGI Global. doi:10.4018/978-1-7998-2736-8.ch004

Chakraborty, S., Chatterjee, S., Das, A., \& Mali, K. (2020). Penalized Fuzzy C-Means Enabled Hybrid Region Growing in Segmenting Medical Images. doi:10.1007/978-981-13-8930-6_3

Chakraborty, S., \& Mali, K. (2020a). An Overview of Biomedical Image Analysis From the Deep Learning Perspective. In Applications of Advanced Machine Intelligence in Computer Vision and Object Recognition: Emerging Research and Opportunities. IGI Global. 10.4018/978-1-7998-2736-8.ch008

Chakraborty, S., \& Mali, K. (2020b). SuFMoFPA: A superpixel and meta-heuristic based fuzzy image segmentation approach to explicate COVID-19 radiological images. Expert Systems with Applications, 114142. Advance online publication. doi:10.1016/j.eswa.2020.114142

Chakraborty, S., \& Bhowmik, S. (2015). Blending roulette wheel selection with simulated annealing for job shop scheduling problem. Michael Faraday IET International Summit 2015, 100(7). 10.1049/cp.2015.1696

Chakraborty, S., \& Bhowmik, S. (2015). An Efficient Approach to Job Shop Scheduling Problem using Simulated Annealing. International Journal of Hybrid Information Technology, 8(11), 273-284. doi:10.14257/ ijhit.2015.8.11.23

Chakraborty, S., Chatterjee, S., Dey, N., Ashour, A. S., Ashour, A. S., Shi, F., \& Mali, K. (2017). Modified cuckoo search algorithm in microscopic image segmentation of hippocampus. Microscopy Research and Technique, 80(10), 1051-1072. doi:10.1002/jemt.22900 PMID:28557041

Chakraborty, S., \& Mali, K. (2020c). Fuzzy Electromagnetism Optimization (FEMO) and its application in biomedical image segmentation. Applied Soft Computing, 97, 106800. doi:10.1016/j.asoc.2020.106800 PMID:33100938

Chakraborty, S., \& Mali, K. (2021). SUFMACS: A machine learning-based robust image segmentation framework for covid-19 radiological image interpretation. Expert Systems with Applications, 115069, 115069. Advance online publication. doi:10.1016/j.eswa.2021.115069 PMID:33897121 
Chakraborty, S., Mali, K., Banerjee, S., Roy, K., Saha, D., Chatterjee, S., Dutta, S., \& Majumder, S. (2018). Bagof-features based classification of dermoscopic images. 20174 th International Conference on Opto-Electronics and Applied Optics, Optronix 2017. doi:10.1109/OPTRONIX.2017.8349977

Chakraborty, S., Mali, K., Chatterjee, S., Banerjee, S., Roy, K., Dutta, N., Bhaumik, N., \& Mazumdar, S. (2018). Dermatological effect of UV rays owing to ozone layer depletion. 2017 4th International Conference on OptoElectronics and Applied Optics, Optronix 2017. doi:10.1109/OPTRONIX.2017.8349975

Chakraborty, S., Seal, A., Roy, M., \& Mali, K. (2016). A novel lossless image encryption method using DNA substitution and chaotic logistic map. International Journal of Security and Its Applications, 10(2), 205-216. Advance online publication. doi:10.14257/ijsia.2016.10.2.19

Chakraborty, S., \& Bhowmik, S. (2013). Job Shop Scheduling using Simulated Annealing. First International Conference on Computation and Communication Advancement, 1(1), 69-73. https://scholar.google.co.in/citat ions? user $=81 \mathrm{hQFaYAAAAJ} \& \mathrm{hl}=\mathrm{en}$

Datta, S., Chakraborty, S., Mali, K., Baneijee, S., Roy, K., Chatterjee, S., Chakraborty, M., \& Bhattacharjee, S. (2017). Optimal usage of pessimistic association rules in cost effective decision making. 2017 4th International Conference on Opto-Electronics and Applied Optics (Optronix), 1-5. doi:10.1109/OPTRONIX.2017.8349976

Dockery, D. W., \& Pope, C. A. III. (1994). Acute respiratory effects of particulate air pollution. Annual Review of Public Health, 15(1), 107-132. doi:10.1146/annurev.pu.15.050194.000543 PMID:8054077

Fang, B., Kim, J. H., Kim, M., \& Yu, J. S. (2009). Ordered hierarchical nanostructured carbon as a highly efficient cathode catalyst support in proton exchange membrane fuel cell. Chemistry of Materials, 21(5), 789-796. doi:10.1021/cm801467y

Fleischer, T., \& Grunwald, A. (2008). Making nanotechnology developments sustainable. A role for technology assessment? Journal of Cleaner Production, 16(8-9), 889-898. doi:10.1016/j.jclepro.2007.04.018

Hore, S., Chakraborty, S., Chatterjee, S., Dey, N., Ashour, A. S., Van Chung, L., \& Le, D.-N. (2016). An integrated interactive technique for image segmentation using stack based seeded region growing and thresholding. Iranian Journal of Electrical and Computer Engineering, 6(6). Advance online publication. doi:10.11591/ijece.v6i6.11801

Hore, S., Chakroborty, S., Ashour, A. S., Dey, N., Ashour, A. S., Sifaki-Pistolla, D., Bhattacharya, T., \& Chaudhuri, S. R. B. (2015). Finding Contours of Hippocampus Brain Cell Using Microscopic Image Analysis. Journal of Advanced Microscopy Research, 10(2), 93-103. doi:10.1166/jamr.2015.1245

Hore, S., Chatterjee, S., Chakraborty, S., \& Shaw, R. K. (2018). Analysis of different feature description algorithm in object recognition. Computer Vision. Concepts, Methodologies, Tools, and Applications. doi:10.4018/9781-5225-5204-8.ch023

Lu, A. H., Hao, G. P., Sun, Q., Zhang, X. Q., \& Li, W. C. (2012). Chemical synthesis of carbon materials with intriguing nanostructure and morphology. In Macromolecular Chemistry and Physics (Vol. 213, Issues 10-11, pp. 1107-1131). John Wiley \& Sons, Ltd. doi:10.1002/macp.201100606

Mali, K., Chakraborty, S., \& Roy, M. (2015). A Study on Statistical Analysis and Security Evaluation Parameters in Image Encryption. IJSRD-International Journal for Scientific Research \& Development, 3. www.ijsrd.com

Mali, K., Chakraborty, S., Seal, A., \& Roy, M. (2015). An Efficient Image Cryptographic Algorithm based on Frequency Domain using Haar Wavelet Transform. International Journal of Security and Its Applications, 9(12), 279-288. doi:10.14257/ijsia.2015.9.12.26

Miller, D. D., \& Brown, E. W. (2018). Artificial Intelligence in Medical Practice: The Question to the Answer? In American Journal of Medicine (Vol. 131, Issue 2, pp. 129-133). Elsevier Inc. doi:10.1016/j.amjmed.2017.10.035

Mondal, S., Bhadra, A., \& Chakraborty, S. (2021). A Smart and Intelligent Irrigation System With a Roadmap Ahead. International Journal of Digital Innovation in the Built Environment, 10(1), 18-33. doi:10.4018/ IJDIBE.2021010102

Pummakarnchana, O., Tripathi, N., \& Dutta, J. (2005). Air pollution monitoring and GIS modeling: A new use of nanotechnology based solid state gas sensors. Science and Technology of Advanced Materials, 6(3-4), 251-255. 10.1016/j.stam.2005.02.003 
Roy, M., Chakraborty, S., Mali, K., Chatterjee, S., Banerjee, S., Chakraborty, A., Biswas, R., Karmakar, J., \& Roy, K. (2017). Biomedical image enhancement based on modified Cuckoo Search and morphology. 2017 8th Annual Industrial Automation and Electromechanical Engineering Conference (IEMECON), 230-235. doi:10.1109/IEMECON.2017.8079595

Roy, M., Mali, K., Chatterjee, S., Chakraborty, S., Debnath, R., \& Sen, S. (2019). A Study on the Applications of the Biomedical Image Encryption Methods for Secured Computer Aided Diagnostics. 2019 Amity International Conference on Artificial Intelligence (AICAI), 881-886. doi:10.1109/AICAI.2019.8701382

Roy, M., Chakraborty, S., Mali, K., Chatterjee, S., Banerjee, S., Mitra, S., Naskar, R., \& Bhattacharjee, A. (2018). Cellular image processing using morphological analysis. 2017 IEEE 8th Annual Ubiquitous Computing, Electronics and Mobile Communication Conference, UEMCON 2017. doi:10.1109/UEMCON.2017.8249037

Sarddar, D., Chakraborty, S., \& Roy, M. (2015). An Efficient Approach to Calculate Dynamic Time Quantum in Round Robin Algorithm for Efficient Load Balancing. International Journal of Computers and Applications, 123(14), 48-52. doi:10.5120/ijca2015905701

Seal, A., Chakraborty, S., \& Mali, K. (2017). A new and resilient image encryption technique based on pixel manipulation, value transformation and visual transformation utilizing single-Level haar wavelet transform. In Advances in Intelligent Systems and Computing (Vol. 458). doi:10.1007/978-981-10-2035-3_61

Silva, T. A., Moraes, F. C., Janegitz, B. C., Fatibello-Filho, O., \& Ganta, D. (2017). Electrochemical biosensors based on nanostructured carbon black: A review. In Journal of Nanomaterials (Vol. 2017). Hindawi Limited. doi: $10.1155 / 2017 / 4571614$

Yang, Z., Ren, J., Zhang, Z., Chen, X., Guan, G., Qiu, L., Zhang, Y., \& Peng, H. (2015). Recent Advancement of Nanostructured Carbon for Energy Applications. In Chemical Reviews (Vol. 115, Issue 11, pp. 5159-5223). American Chemical Society. doi:10.1021/cr5006217 
Samrat Mondal is a student of Department of Electronics \& Telecommunication Engineering, M.B.C. Institute of Engineering \& Technology.

Avishek Bhadra is a student of Department of Electronics \& Telecommunication Engineering, M.B.C. Institute of Engineering \& Technology.

Shouvik Chakraborty is a Lecturer in Computer Science \& Technology, In-charge, Robotics and Innovation Laboratory and the Internal Coordinator of the Burdwan Regional Office, Directorate of Vocational Education and Training at M.B.C. Institute of Engineering \& Technology (Government of West Bengal), Purba Bardhaman, Sadhanpur. He is currently pursuing Ph.D. (Former DST INSPIRE Fellow) in Computer Science and Engineering from the University of Kalyani, West Bengal, India. He received his M. Tech. in Computer Science and Engineering from the University of Kalyani, in 2016. He received his B. Tech. in Computer Science and Engineering from Hooghly Engineering \& Technology College under Maulana Abul Kalam Azad University of Technology (Formerly known as West Bengal University of Technology), West Bengal, India in 2014. He has received AICTE National Fellowship during his Master of Technology. He secured First class First position in the Master of Technology. He has cleared Graduate Aptitude Test in Engineering (GATE, 7 times), UGC National Eligibility Test (UGC NET LS 2 times, LS \& JRF 2 times) and West Bengal State Eligibility Test (SET). He is an associate member of the Institute of Research Engineers and Doctors (Universal Association of Computer and Electronics Engineers) (USA). He is a member of the International Association of Computer Science and Information Technology (Singapore), International Association of Engineers (Hong Kong) International Computer Science and Engineering Society, International Economics Development Research Center (Hong Kong), Machine Intelligence Research Labs (USA) and The Society of Digital Information and Wireless Communications. His research interests include Soft and Evolutionary Computing, Digital Image Processing, Bio-medical Image Analysis, Pattern Recognition, Machine Learning and Optimization Techniques. He has published one book, several book chapters, journal articles and published and presented many research papers in different reputed international and national conferences. He is one of the editorial review board member of IJCVIP, ASTESJ, IJSVR and reviewer of many reputed international journals like IEEE Access, IEEE Transactions on Emerging Topics in Computational Intelligence, Informatics in Medicine Unlocked (Elsevier), IJAMC (IGI Global), Journal of Experimental \& Theoretical Artificial Intelligence (Taylor \& Francis) etc. $\mathrm{He}$ is the recipient of multiple best paper awards in different international conferences. 